International Journal of Medical Anesthesiology 2021; 4(1): 47-49

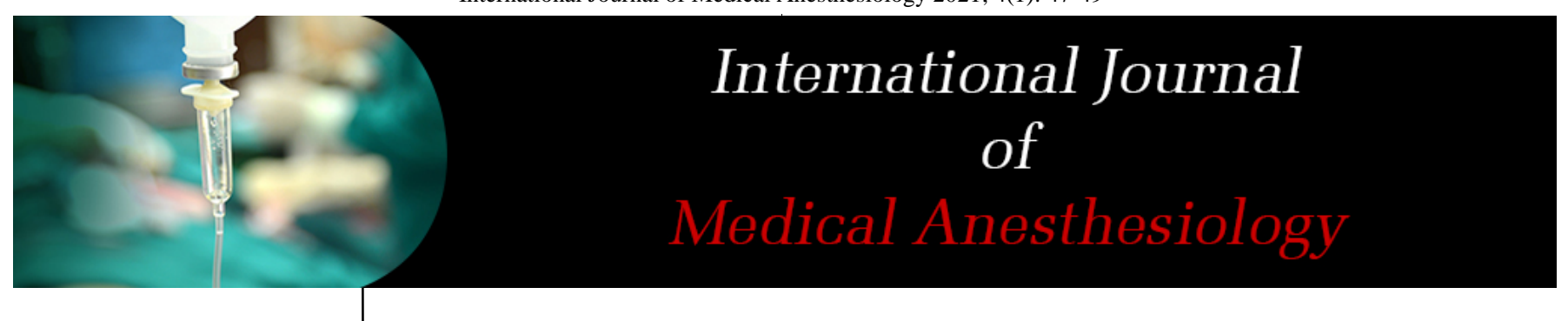

E-ISSN: 2664-3774

P-ISSN: 2664-3766

www.anesthesiologypaper.com

IJMA 2021; 4(1): 47-49

Received: 15-11-2020

Accepted: 28-12-2020

Dr. Diganta Mohanty

Senior Resident,

Department of Anaesthesia

and Critical Care Medicine,

Amri Hospital Pvt. Ltd.,

Bhubaneswar, Odisha, India

Dr. Chandrasekhar Behera

LTRMO, City Hospital

Berhempur, Odisha, India
Corresponding Author: Dr. Chandrasekhar Behera LTRMO, City Hospital Berhempur, Odisha, India

\section{A study to observe the endotracheal tube cuff pressure during percutaneous dilatational tracheostomy}

\author{
Dr. Diganta Mohanty and Dr. Chandrasekhar Behera
}

DOI: $\underline{\text { https://doi.org/10.33545/26643766.2021.v4.i1a.295 }}$

\begin{abstract}
Aim: The present study was undertaken to observe the endotracheal tube cuff pressure by manual and automated methods during percutaneous dilatational tracheostomy.

Materials and Methods: The study recruited 60 patients of the age group of 30-60 years 20 and 50 yrs of ASA grade I/II and MPG I/II. Informed consent was obtained from all the participants and confidentiality of data was maintained. Patients with severe complications were excluded from the study. After recruiting, patients were divided into two groups with 30 participants in each group. Group 1 cuff pressure was monitored manually and group 2 cuff pressure was monitored automatically.

Results: Demographic data was not significantly different between the groups. There was no air leak from side of ETTc. Airway pressure was significantly high in group 1. No significant difference was observed in tidal volume in both groups. $\mathrm{P}$ value for baseline pressure is 0.7504 . $\mathrm{P}$ value for pressure set up after monitoring cuff is 0.4271 . P value for pressure set up after monitoring cuff after one hour is 0.2885. P value for pressure set up after monitoring cuff after two hours is 0.2095. By conventional criteria, this difference is considered to be not statistically significant.

Conclusion: The study results confirm that both manual and automated methods are equally effective in the maintenance of respiratory functions. Further detailed studies are necessary in this area.
\end{abstract}

Keywords: Endotracheal tube, cuff pressure, tracheostomy

\section{Introduction}

Tracheostomy is age old technique which can be performed surgically or percutaneously. Percutaneous technique has little more advantageous than the manual method ${ }^{[1]}$. Because this method is preferred to be performed bedside patients. Endo tracheal tube is most common practice in crtical care setting to deliver anesthesia and to maintain the respiratory functions of the patients ${ }^{[2]}$. Cuffed tube usage ensures further safety in delivering the appropriate pressure and also ensures further safety of the technique. At the same time, monitoring and regulating the pressure of cuff also important ${ }^{[3]}$. It can be performed both manual and automated methods. Both methods have its advantages and disadvantages. However, there are very few studies that compared these two methods. Hence, the present study was undertaken to observe the endotracheal tube cuff pressure by manual and automated methods during percutaneous dilatational tracheostomy.

\section{Materials and methods \\ Study design: Observational study}

\section{Sampling method: Convenient sampling}

Study population: The study recruited 60 patients of the age group of 30-60 years 20 and 50 yrs of ASA grade I/II and MPG I/II. Informed consent was obtained from all the participants and confidentiality of data was maintained. Patients with severe complications were excluded from the study. After recruiting, patients were divided into two groups with 30 participants in each group. Group 1 cuff pressure was monitored manually and group 2 cuff pressure was monitored automatically.

Data collection: All participants underwent thorough physical examination. All measurements were performed using standard methods in the literature ${ }^{[3-6]}$. 
Ethical considerations: The study proposal was approved by the institutional ethics committee after satisfying the queries adequately. The study followed all the guidelines as per the ICMR guidelines. Written informed consent was obtained from all the parents of the participants before the commencement of the study. Information related to the patients was kept confidential.

Data analysis: The statistical software SPSS 18.0 version was used to analyze the data. The significance of difference was tested using the student t test. The probability value less than 0.05 were considered significant.

\section{Results}

Table no 1 presents the demographic data of participants. The two-tailed $\mathrm{P}$ value equals 0.2778 for age. By conventional criteria, this difference is considered to be not statistically significant. The $\mathrm{P}$ value for weight parameter is 0.5704. By conventional criteria, this difference is considered to be not statistically significant. The $\mathrm{P}$ value for height parameter is 0.0601 . By conventional criteria, this difference is considered to be not quite statistically significant. Table 2 presents the respiratory parameters of participants. There was no air leak from side of ETTc. Airway pressure was significantly high in group 1 . No significant difference was observed in tidal volume in both groups. EtCo2 was significantly different between the groups. $\mathrm{P}$ value for baseline pressure is 0.7504 . By conventional criteria, this difference is considered to be not statistically significant. P value for pressure set up after monitoring cuff is 0.4271. By conventional criteria, this difference is considered to be not statistically significant. $\mathrm{P}$ value for pressure set up after monitoring cuff after one hour is 0.2885 . By conventional criteria, this difference is considered to be not statistically significant. $\mathrm{P}$ value for pressure set up after monitoring cuff after two hours is 0.2095. By conventional criteria, this difference is considered to be not statistically significant.

Table 1: Demographic data of participants

\begin{tabular}{|c|c|c|c|}
\hline Refractive error & Group 1 (n=30) & Group 2 (n=30) & P value \\
\hline Age (years) & $52 \pm 8$ & $50 \pm 6$ & 0.2778 \\
\hline Gender (M:F) & $12: 18$ & $14: 16$ & \\
\hline Weight (kg) & $62 \pm 5.3$ & $61 \pm 8$ & 0.5704 \\
\hline Height (cm) & $154 \pm 12.76$ & $160 \pm 11.44$ & 0.0601 \\
\hline
\end{tabular}

Data was presented as mean and SD

Table 2: Respiratory parameters of participants

\begin{tabular}{|c|c|c|c|}
\hline Parameters & $\begin{array}{c}\text { Group 1 } \\
(\mathbf{n}=\mathbf{3 0})\end{array}$ & $\begin{array}{c}\text { Group 2 } \\
(\mathbf{n}=\mathbf{3 0})\end{array}$ & P value \\
\hline EtCo2 & $30 \pm 2.344$ & $32 \pm 3.43$ & $0.0107^{*}$ \\
\hline Tidal volume & $482 \pm 24.44$ & $470 \pm 40.33$ & 0.1687 \\
\hline Airway pressure & $18 \pm 0.244$ & $17.6 \pm 0.622$ & $0.0018^{*}$ \\
\hline Air leak from side of ETTc & Nil & Nil & \\
\hline
\end{tabular}

Data was presented as mean and SD. (*P value less than 0.05 was significant)

Table 3: ETTc pressure in both the groups

\begin{tabular}{|c|c|c|c|}
\hline Pressure (cm of H2O) & $\begin{array}{c}\text { Group 1 } \\
(\mathbf{n = 3 0 )}\end{array}$ & $\begin{array}{c}\text { Group 2 } \\
\mathbf{( n = 3 0 )}\end{array}$ & P value \\
\hline Baseline pressure & $52 \pm 11.55$ & $51 \pm 12.66$ & 0.7504 \\
\hline After cuff pressure monitor & $26 \pm 10.43$ & $24 \pm 8.88$ & 0.4271 \\
\hline After 1 hr & $27 \pm 7.62$ & $25 \pm 6.82$ & 0.2885 \\
\hline After 2 hours & $27 \pm 6.32$ & $25 \pm 5.88$ & 0.2095 \\
\hline
\end{tabular}

Data was presented as mean and SD. (*P value less than 0.05 was significant)

\section{Discussion}

The present study was undertaken to observe the endotracheal tube cuff pressure by manual and automated methods during percutaneous dilatational tracheostomy. Demographic data was not significantly different between the groups. There was no air leak from side of ETTc.

$\mathrm{P}$ value for baseline pressure is 0.7504 . $\mathrm{P}$ value for pressure set up after monitoring cuff is 0.4271 . Tidal volume was not significantly different between groups. $\mathrm{P}$ value for pressure set up after monitoring cuff after one hour is 0.2885 . $\mathrm{P}$ value for pressure set up after monitoring cuff after two hours is 0.2095. By conventional criteria, this difference is considered to be not statistically significant.

In critical care setting, there is a strong need to maintain the cuff pressure to maintain smooth respiratory functions ${ }^{[7]}$. The available methods are manual and automated methods for this task. There was studies individually conducted on each of these methods but the studies comparing these methods are lacking ${ }^{[8]}$. There exist studies supporting that manual method has high accuracy ${ }^{[9,10]}$. At the same time there are studies supporting automated methods also ${ }^{[11,12]}$. The study compared these two methods and assessed the effectiveness. Both methods were found to be equally effective.

\section{Conclusion}

The study results confirm that both manual and automated methods are equally effective in the maintenance of respiratory functions. Further detailed studies are necessary in this area.

\section{Source of funding: Self-funding}

\section{Conflicts of interest: None declared}

\section{References}

1. Nordin U, Lindholm CE, Wolgast M. Blood flow in the rabbit tracheal mucosa under normal conditions and under the influence of tracheal intubation. Acta Anaesthesiol Scand 1977;21:81-94.

2. Seegobin RD, Van Hasselt GL. Endotracheal cuff pressure and tracheal mucosal blood flow: Endoscopic study of effects of four large volume cuffs. Br Med J (Clin Res Ed) 1984;288:965-8.

3. Reed MF, Mathisen DJ. Tracheoesophageal fistula. Chest Surg Clin N Am 2003;13:271-89.

4. Ganner C. The accurate measurement of endotracheal tube cuff pressures. Br J Nurs 2001;10:1127-34.

5. Lomholt N. A device for measuring the lateral wall cuff pressure of endotracheal tubes. Acta Anaesthesiol Scand 1992;36:775-8.

6. Foroughi V, Sripada R. Sensitivity of tactile examination of endotracheal tube intra-cuff pressure. [abstract] Anesthesiology 1997;87:965A.

7. Sengupta P, Sessler DI, Maglinger P, Wells S, Vogt A, Durrani J et al. Endotracheal tube cuff pressure in three hospitals, and the volume required to produce an appropriate cuff pressure. BMC Anesthesiol 2004;4:8.

8. Stewart SL, Secrest JA, Norwood BR, Zachary R. A comparison of endotracheal tube cuff pressures using estimation techniques and direct intracuff measurement. AANA J 2003;71:443-7.

9. Braz JR, Navarro LH, Takata IH, Nascimento Junior P. Endotracheal tube cuff pressure: Need for precise 
measurement. Sao Paulo Med J 1999;117:243-7.

10. Lien TC, Wang JH. Incidence of pulmonary aspiration with different kinds of artificial airways. Zhonghua Yi Xue Za Zhi (Taipei) 1992;49:348-53.

11. Parwani V, Hahn I, Hsu B, Hoffman R. Experienced emergency physicians cannot safely or accurately inflate endotracheal tube cuffs or estimate endotracheal tube cuff pressure using standard technique [abstract] Acad Emerg Med 2004;11:490.

12. Guyton DC, Barlow MR, Besselievre TR. Influence of airway pressure on minimum occlusive endotracheal tube cuff pressure. Crit Care Med 1997;25:91-4. 